\title{
Evaluation of long-term vegetation trends for northeastern of Iraq: Mosul, Kirkuk and Salah al-Din
}

\author{
Ahmad S. Muhaimeed ${ }^{1}$, Al-HednySuhad $\mathrm{M}^{2}$ \\ 1-Department of Soil and Water Science, College of Agriculture, Baghdad University, Iraq \\ *PhD student, Dept. of Soil and Water Science, College of Agriculture, Baghdad University, Iraq
}

\begin{abstract}
Climate change is the major global challenge facing water resources managers. In this study, the climate change in term of rainfall fluctuation in the northeastern of Iraq (Mosul, Kirkuk and Salah al-Din) have been investigated using a set of data containing monthly precipitation for period from 1980 to 2010, and MODIS time series images for period from 2000 to 2010. MODIS data have been used to calculate NDVI (normalized difference vegetation index). The highest NDVI values were 0.33 in 2001, 0.39 in 2003 and 0.20 in 2001 for Mosul, Kirkuk and Salah al-Din respectively, while the lowest NDVI values were $0.10 \mathrm{in}, 0.19$ and 0.13 in 2008 for three mentioned governorates respectively. The NDVI and rainfall was found to be highly correlated 0.83, 0.70 and 0.72 for Mosul, Kirkuk and Salah al-Din respectively. The negative trends in NDVI values mirror non-uniformity of rainfall patterns and moisture shortage during the growing season. The biomass status in 2010 highlighted that prolong of drought conditions in 2008 and 2009 caused losses in soil productivity (decline of soil quality) is cumulative. Results of this study verify needing to use this tools (NDVI), along with data from soil survey, fertility tests, and other monitoring data to identify areas with problem (where, when, and how problems arise) to formulate practical management decisions.
\end{abstract}

Keywords: NDVI, Drought monitoring, remote sensing, Iraq agriculture.

\section{Introduction}

Drought is classified as the environmental hazard and natural disaster that depreciates the sustainable development of society (Shaheen and Baig, 2011). Its long lasting impacts badly increasing its extent on agricultural production, livestock, physical environment and overall economy. Over the last three decades, many world regions have suffered from water crises and drought caused serious impacts on local economies (Ghulam, et al., 2008). Iraq, Syria, Turkey and Iran, have been dealing with decreased rainfall affected negatively the agricultural sector, livelihood system, employment and water allowable quantity and quality (UNDP, 2010).

Drought may be treated as a meteorological, hydrological, or agricultural phenomenon. In each one the variable representing water availability are different. Meteorological drought is a situation of rainfall shortage from normal precipitation over an area. Agricultural drought occurs when soil moisture and rainfall are inadequate during the growing season. Hydrological drought represents the long-term meteorological drought that cause a decline in reservoirs, lakes, streams, rivers, and groundwater level (Rathore, 2004). Drought is characterized as a multi-dimensional phenomenon (severity, duration, magnitude). Attention has been paid so far to simplify these dimensions to reach a practical way to assess the severity of drought.

The mitigation of drought impact requires rapid and continuous real time data. Remote sensing technology represents an excellent tool to collect data in digital form rapidly and repetitively at various levels (global and regional levels). The space technology has outstanding possibilities to provide baseline data of natural resources, soil degradation, climate change, and other important area of concern. In recent years, the development in space technology to address drought issues (drought detection, monitoring, and assessment) have been dealt with the current, before, during, and after-situation of drought event. According to Kogan (1990) drought can be detected 4-6 weeks earlier than before, and its impact can be diagnosed far in advance of the most critical stage of plant growth (harvest stage). As a slow onset disaster, drought can lead to socioeconomic instability especially in developing countries by reducing crop production levels and setback in agricultural sector. For that reason, there is a need of monitoring and reporting of economical and environmental impacts of drought in vulnerable areas.

Vegetation is the first feature can be affected by drought; as a result remote sensing indices have been developed for the quantification of drought based on brightness values of the land cover types. Many of vegetation indices are introduced using ratios of visible, near-infrared, and mid-infrared portions of the electromagnetic spectrum (Tucker, 1979; Goward, et al., 1991 and Yang, et al., 1998). The Normalized Difference Vegetation Index (NDVI) is suggested as an indicator of vegetation health and density by Tucker (1979).Since climate is a key factor affecting vegetation conditions, NDVI has been widely used at regional and global scales to identify weather impacts on crop growth conditions and yields ( $\mathrm{Li}$, et al., 2004; VicenteSerrano, et al., 2006 and Jain, et al., 2009).Based on the positive and significant correlation between NDVI and 
rainfall anomalies, several studies concluded that the NDVI was the most common form of vegetation index can be used effectively in drought early warning system (Anyamba and Tucker, 2005; Bhuiyana, et al., 2006; Martiny, et al., 2006; Murthy, et al., 2009 and Quiring and Ganesh, 2010).

Medium resolution sensors such as MODIS provide daily coverage of the earth, and so weather events are much less of an obstacle. MODIS have been extensive used in drought studies, as it monitors earth surface continuously, freely accessible and furthermore it's broadly recognized around the world (Persendt, 2009). In recent years, the space techniques have been used widely to provide a comprehensive view on drought situation. Chopra (2006) pointed that, the RS and GIS can be effectively used for monitoring and assessing the food grain production and he stressed upon the use of RS and GIS in the field of drought risk evaluation. According to Jain, etal. (2010) the integrated analysis of ground measured data and satellite data has a great potential in drought monitoring.

In general, remote sensing and GIS have played a key role in studying different types of drought and obtained the risk map for area facing drought, thereby management plans can be formulated by the government authorities to cope with the disastrous effects. From this view, this study focuses on evaluate long-term vegetation trends for the last decades and its relation to rainfall shortages. Further, the study shows the application of vegetation condition indices for drought monitoring in Iraq.

\section{1- Study Area}

\section{Data and Methods}

Mosul, Kirkuk, and Salah al-Din governorates are located on longitude 41 to 43 and from latitude 34 to 36. The region shares its borders with Syria in the west, Kurdistan region in the north, Diyala in the east, and Baghdad and Anbar in the south (figure 1). Mosul is Iraq's third largest city located in northern Iraq, its area is $37,323 \mathrm{Km}^{2}$ ( $8.6 \%$ of Iraq). Agriculture is a key component of Mosul economy, particularly cereal production (IUA, 2011). Kirkuk is one of the ancient provinces in Iraq with significant geographic location linking between central and northern Iraq, it is situated in the north east of Iraq. The governorate's area is $9,679 \mathrm{~km}^{2}$ (PRT/USAID/RTI, 2007). Salah ad-Din located north of Baghdad, its area is $24,075 \mathrm{Km}^{2}$. Salah ad-Din's population is one of the most rural in Iraq. Agriculture provides $36 \%$ of the jobs in governorate (IUA, 2011).

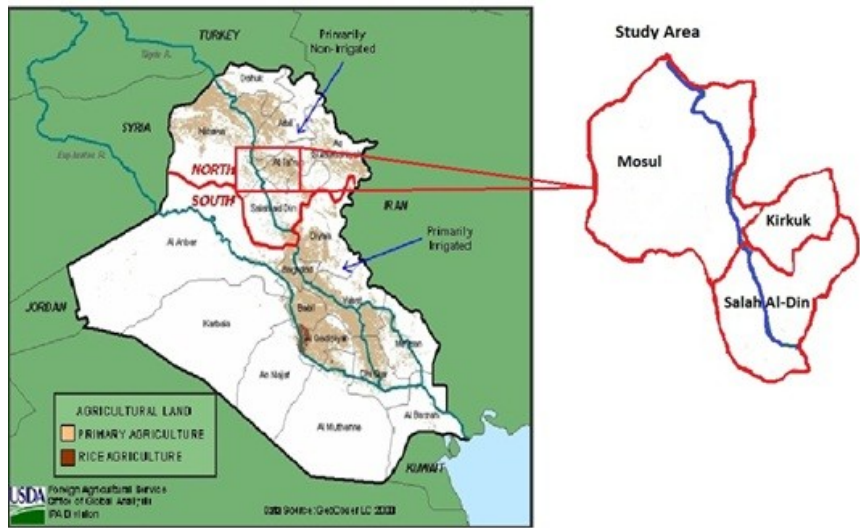

Figure (1): Location and extent of the study area.

The climate of study area is classified as semi-arid, subtropical, Mediterrian climate, which is characterized by a hot dry summer and cold winter. Most of rain falls in winter and spring (October through May). There is no rainfall during summer (the period from June to September). Theclimatic data for period from 1980 to 2010 of Mosul governorate are taken from 7 meteorological stations: Mosul, Sinjar, Rabiha, Telafr, Telabta, Al-Baaj and Mkhmoor. Kirkuk andTuz stations provided climatic data for Kirkuk and Sammara, Baiji and Tikrit stations provided climatic data for Salah al-Din (table 1).

Table (1): Average monthly climatic data for period from 1980 to 2010 taken from meteorological stations within study area.

\begin{tabular}{|c|c|c|c|c|c|c|c|c|c|c|c|c|}
\hline \multirow[t]{2}{*}{ Governorate } & Jan. & Feb. & Mar. & Apr. & May & Jun. & Jul. & Aug. & Sep. & Oct. & Nov. & Dec. \\
\hline & \multicolumn{12}{|c|}{ Precipitation (mm) } \\
\hline Mosul & 61.5 & 54.3 & 58.9 & 31.1 & 16.2 & 1.2 & 0.1 & 0.0 & 0.6 & 16.9 & 40.7 & 57.3 \\
\hline Kirkuk & 61.9 & 56.3 & 43.8 & 36.0 & 11.7 & 0.4 & 0.3 & 0.1 & 0.7 & 15.2 & 43.1 & 51.9 \\
\hline Salah al-Din & 33.0 & 29.7 & 28.1 & 17.0 & 9.7 & 0.2 & 0.0 & 0.0 & 0.7 & 9.3 & 25.6 & 32.7 \\
\hline \multicolumn{13}{|c|}{ Min. Temperature $\mathrm{C}^{0}$} \\
\hline Mosul & 3.4 & 4.6 & 8.0 & 12.9 & 18.3 & 23.7 & 27.0 & 26.6 & 22.1 & 16.6 & 9.3 & 4.9 \\
\hline Kirkuk & 4.9 & 6.3 & 9.8 & 14.9 & 21.0 & 25.6 & 28.2 & 27.8 & 24.1 & 18.6 & 11.2 & 6.4 \\
\hline Salah al-Din & 4.2 & 5.8 & 9.7 & 15.3 & 20.9 & 25.1 & 27.9 & 27.3 & 23.1 & $\begin{array}{l}17.8 \\
\end{array}$ & 10.3 & 5.8 \\
\hline
\end{tabular}




\begin{tabular}{|l|c|c|c|c|c|c|c|c|c|c|c|c|}
\hline \multicolumn{10}{|c|}{ Max. Temperature $\mathrm{C}^{\mathrm{0}}$} \\
\hline Mosul & 11.5 & 13.7 & 18.4 & 24.5 & 31.6 & 37.5 & 41.3 & 40.8 & 36.0 & 29.2 & 20.1 & 14.2 \\
\hline Kirkuk & 14.1 & 16.1 & 20.9 & 27.0 & 34.3 & 40.3 & 43.3 & 42.9 & 38.2 & 31.6 & 22.7 & 16.5 \\
\hline Salah al-Din & 14.6 & 17.2 & 22.5 & 28.9 & 35.6 & 40.7 & 43.9 & 43.6 & 39.5 & 32.6 & 23.3 & 16.6 \\
\hline
\end{tabular}

The dominant soil orders in the study area are: Aridisols, Inceptisols and some Mollisols in Mosul; Aridisols and Entisols in Kirkuk and Salah al-Din (Al-Agidi, 1986; Muhaimeed, 1991; Muhaimeed, et al., 2000; Muhaimeed and Mohammed, 2001 and Muhaimeed, 2012). All these soil orders represent soils with beginning degree of soil development or event very recent soils without any status of development. This is due, mainly to the effect of arid or semi arid climatic conditions. Wheat and Barley are the main crops in the study area, they cover the largest section of the total farmed land (rain based irrigation) (IUA, 2010).

\section{2- NDVI Analysis}

The satellite data that was used is derived from the MODIS sensor. MODIS is the primary sensor for monitoring the global ecosystems for the NASA Earth Observing System (EOS) program. 16-day composites images at $1 \mathrm{Km}$ resolution are directly downloadable from the USGS data center (http://glovis.usgs.gov). For each governorate ten 16-day composites (7-23 April) were downloaded for period from 2000-2010. All of images were re-projected into GIS friendly format (TIFF) using MODIS reprojection tool from USGS. 16-day compositing periods minimize cloud contamination, hence most images downloaded had less than $10 \%$ cloud cover (data is cloud free). Most of the image pre-processing was already on the downloaded MODIS; hence images were only geo-referencing to calculate:

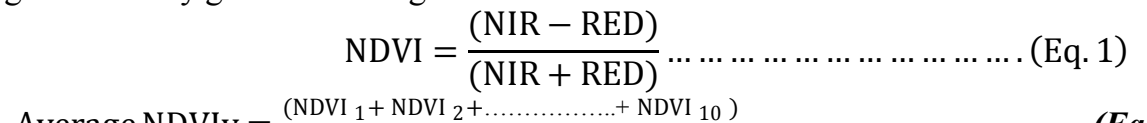

Average NDVIy $=\frac{\left(\mathrm{NDVI}_{1}+\mathrm{NDVI}_{2}+\ldots \ldots \ldots \ldots \ldots+\mathrm{NDVI}_{10}\right)}{10} \ldots \ldots \ldots \ldots \ldots \ldots \ldots \ldots(\boldsymbol{E q} .2)$

Where NDVIy is NDVI across study period, NDVI1 (7-23 April 2000), NDVI2 (7-23 April 2001), ........ NDVI10 (7-23 April 2010).

$$
\text { NDVI Anomaly i }=\left[\frac{(\text { NDVIi }- \text { Mean NDVI) }}{(\text { Mean NDVI })} * 100\right] \ldots \ldots(\boldsymbol{E q} \cdot \mathbf{3})
$$

Where NDVI $\mathrm{i}=$ NDVI in the year and Mean NDVI =long term mean NDVI in the period study.

The resulting NDVI anomaly percentage assigned to respective grid cell was reclassified into five drought severity classes in table 2 (Chopra, 2006).

Table (2): Agricultural drought risk classification using NDVI anomalies

\begin{tabular}{|c|c|}
\hline Percent of NDVI Anomalies & Class \\
\hline $0 \%$ to $-10 \%$ & Slight drought \\
\hline$-10 \%$ to $-20 \%$ & Moderately drought \\
\hline$-20 \%$ to $-30 \%$ & Severe drought \\
\hline Less than $-30 \%$ & Very Severe drought \\
\hline
\end{tabular}

Finally, correlation analysis was performed between the NDVI values and annual rainfall. Software such as ESRI ArcGIS 10.0, and ENVI 4.0, are used for image processing and analyzing software and Tableau 7.0 and Microsoft excel for arrangement data.

\section{1- Spatial and seasonal pattern of NDVI}

\section{III.Results and Discussion}

Figures 2 through 4 show NDVI maps in April for period (2000 to 2010) for Mosul, Kirkuk, and Salah al-Din. Figures give you an idea about the amount and distribution of vegetations in studied governorate maps which reflect the vegetation situation and greenness. The highest average NDVI values observed were 0.33 and 0.20 in 2000/01 for Mosul and Salah al-Din respectively and 0.39 in 2002/03 for Kirkuk. The lowest NDVI values observed were 0.10, 0.19, and 0.13 in 2007/08 for Mosul, Kirkuk, and Salah al-Din respectively. NDVI has been found to be lowest due to the extremely unfavorable weather. The year 2007/08 was a year of drought with precipitation levels much below the normal. Maximum vegetation is developed in years with optimal weather; since such weather encourages efficient use of ecosystem resources (like an increase in the rate of soil nutrition uptake). In contrast, lake of water in drought years reduces the amount of soil nutrition uptake which suppresses vegetation growth through a reduction in ecosystem resources. The pattern of change of NDVI (figures 2, 3 and 4) are generally representing the seasonal fluctuation between the early rainy season (October, November, and December) and the main rainy season (January, February, March, and April). Season 2007/08 started and ends with very unfavorable conditions making planting of crops difficult and reducing harvest. 

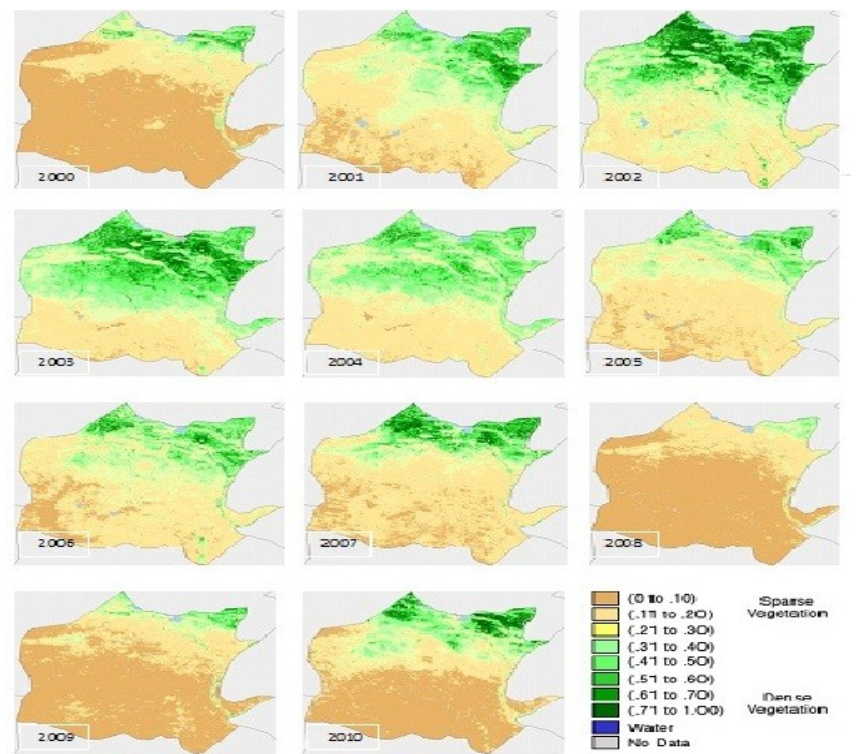

Figure (2): NDVI maps in (07 - 23 April) for period from 2000 - 2010 for Mosul.
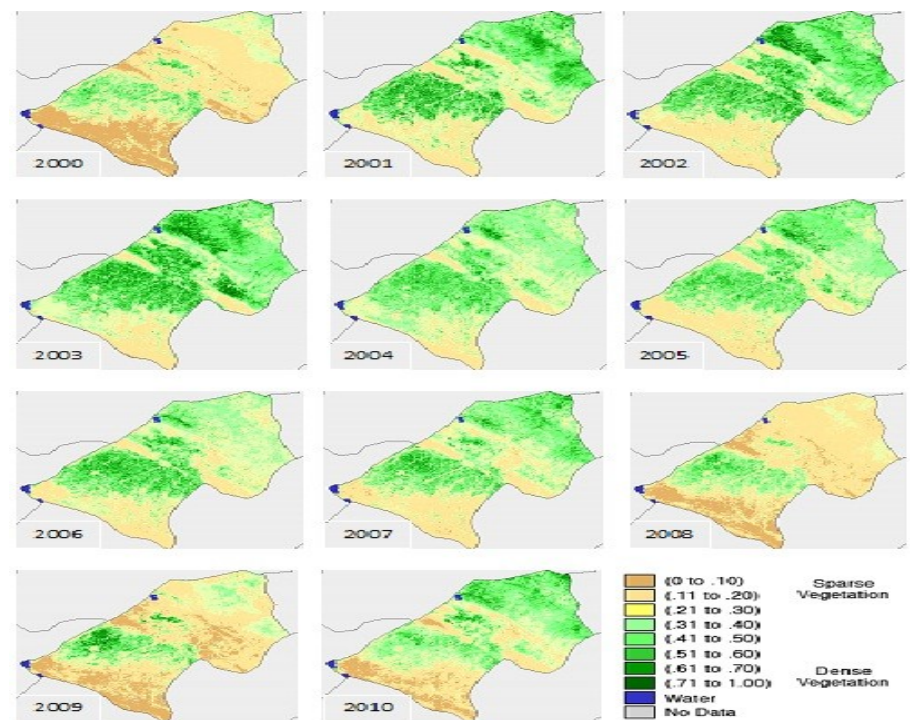

Figure (3): NDVI maps in (07 - 23 April) for period from 2000 - 2010 for Kirkuk.
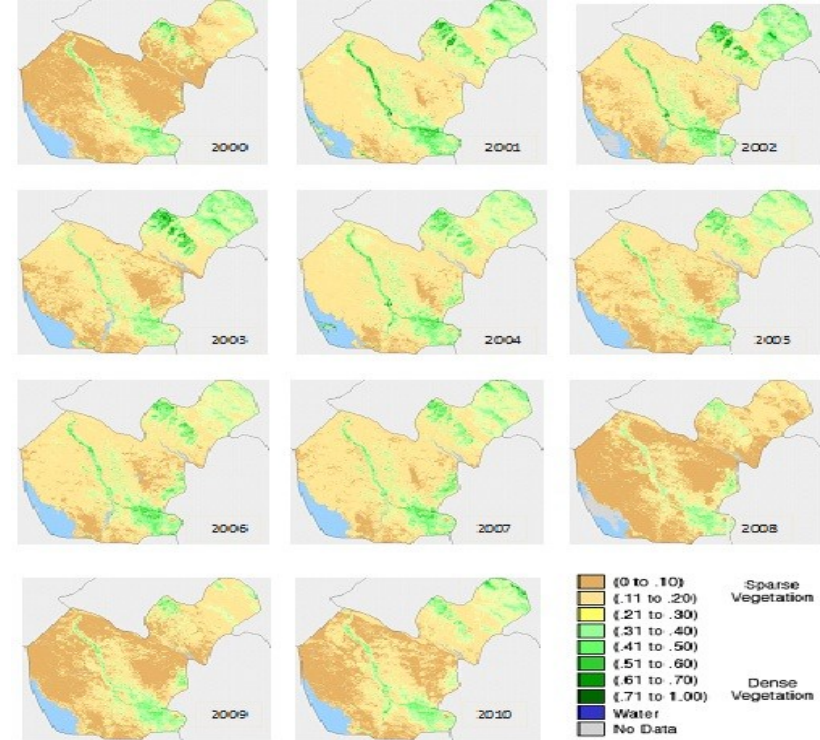

Figure (4): NDVI maps in (07 - 23 April) for period from 2000 - 2010 for Salah al-Din. 
During seasons 2000/01, 2002/03 started with near normal conditions the three governorates received good rains during the first half of the rainy season (October to December) and consequently led to increase vegetation density. Season 2008/09 clearly reflects low dense vegetations illustrated by the dry conditions from 2007/08 season continue into season 2008/09. Figures (2 and 3) reflect the fluctuation of NDVI values in relative to the changes in local weather conditions in Mosul and Kirkuk, while figure 4 clearly show a little stable NDVI patterns in Salah al-Din. This can be attributed to irrigation farming throughout the year and are not influenced much by variability in rainfall.

The results of the NDVI analysis show the sensitivity of NDVI to detect drought events and seasonal vegetation dynamics across all seasons. These results are in good agreements with many studies of NDVI time series to exam the response of vegetation vigor to climatic variations of variables like rainfall to understand causes of observed changes in vegetation greenness (Fensholt and Proud, 2012; Fensholt and Rasmussen, 2011; Eastman, et al., 2009). The results obtained in their study reflect the possibility of using satellite images index (like NDVI) to monitor drought under crop development and measure the degree of stress of crop cover due to water stress conditions.

\section{2- NDVI difference images}

Figure (5) puts on display the NDVI difference maps between NDVI maps in 2008 and 2001 for all three studied governorates (Mosul, Kirkuk, and Salah al-Din). The difference images calculated by using the following formula:

$$
\mathrm{NDVI}_{\text {diff }}=\mathrm{NDVI}_{008}-\mathrm{NDVI}_{2001}
$$

NDVI difference images give more insight into drought onset and severity, it can be clearly observed that the vegetation in 2008 were worse than 2001 over whole study area. The figure shows slight to severe decrease of vegetation for large parts of whole study governorates. With help of NDVI images difference the regional dimension impacts on vegetation conditions could be detected and vulnerable area highlighted. It can be obviously observed that the largest affected area were in Mosul, while the lowest affected area was in Salah al-Din.

The findings of this study verify the change detection as a successful technique to compare changes in crop yield and provide details into what was happening in very severe drought year (2008) compared to the high vegetation dens year (2001). The efficient monitoring methods involve remote sensing technology were proved by (Owrangi, et al., 2011; Bajgiran, et al., 2008; and Gross, 2005). They pointed out that the analyses of monthly/yearly drought dynamics making both quantitative and visual comparisons of drought dynamics in meteorological term, and vegetation domains in agricultural drought term.
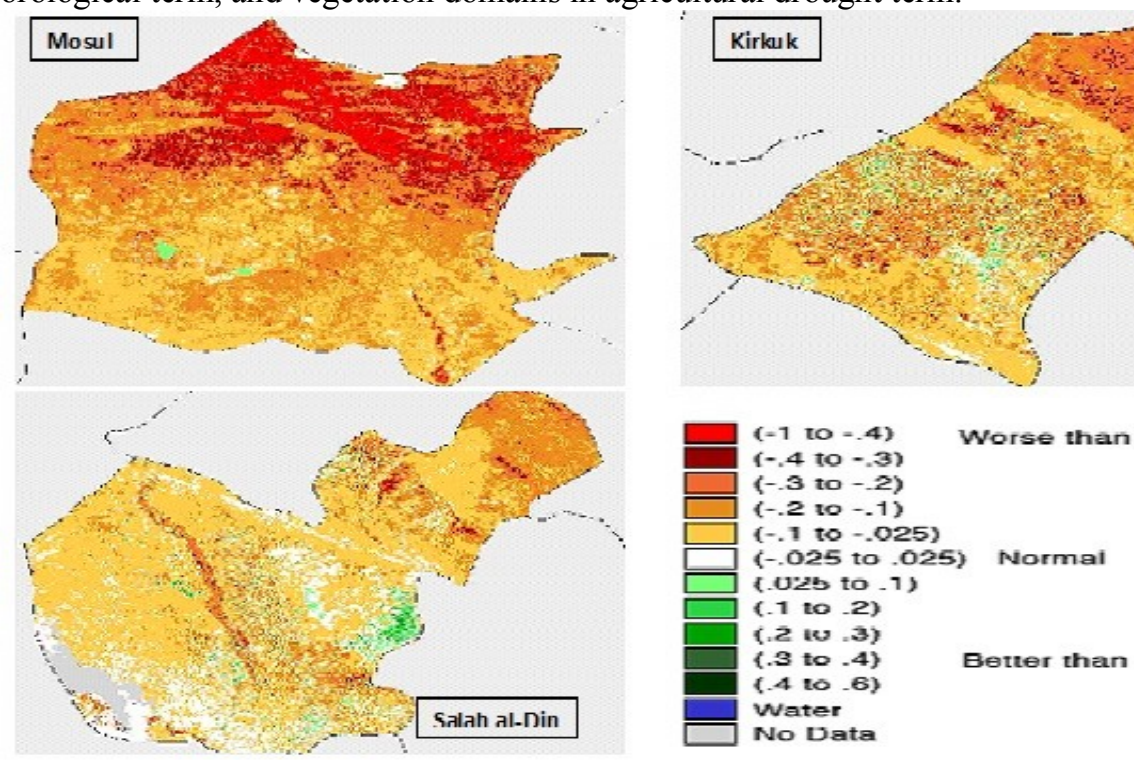

Figure (5): NDVI difference maps between NDVI maps in 2008 and NDVI maps in 2001 for the study area.

\section{3- NDVI- Rainfall relationship}

A good agreement is observed between the peak NDVI and the annual rainfall. Figure 6 displays the variations of NDVI along with annual rainfall in Mosul, Kirkuk and Salah al-Din for period (2001-2010). The results indicated to relatively good agreements are between the lowest NDVI values and the lowest annual rainfall in 2008 for all studied governorates (Mosul, Kirkuk and Salah al-Din), and between the highest NDVI values and the highest annual rainfall over the period (2001-2010). During this period there were considerably 
year-year variations in both NDVI and rainfall. As the figure 6 shows that the NDVI values sharply declined with decreasing of rainfall amount (responded more rapidly to rainfall in drought years) mostly in 2008. By contrast, responded more slowly to rainfall during wet years like 2004 and 2006 in Mosul and Kirkuk respectively.
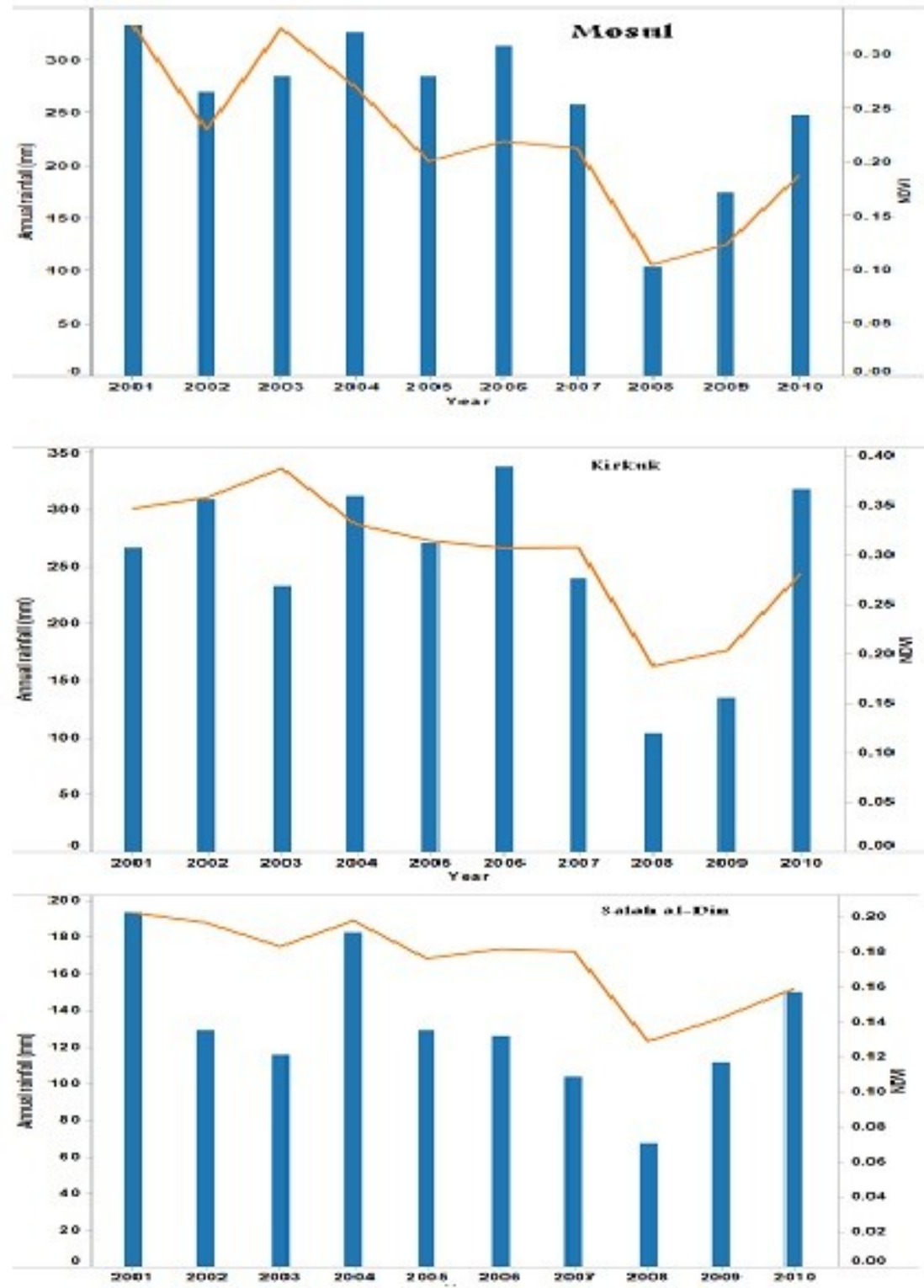

Figure (6): Variations of NDVI with annual rainfall for Mosul, Kirkuk, and Salah al-Din for period 2001-2010.

In order to study the statistical relationship between NDVI and rainfall, correlation analysis was performed between the values of vegetation index (NDVI) and annual rainfall for whole studied governorates during the period (2001-2010). Figure 7 exhibits the results of such correlations. The results of the correlation were significance in all governorates with values $0.83,0.70$, and 0.72 for Mosul, Kirkuk, and Salah al-Din respectively. Results showed that the correlation coefficient for Mosul was higher than both for Kirkuk and Salah al-Din, these results explain clearly that the agricultural pattern in Mosul mostly depends on rainfall compared with agricultural pattern in Kirkuk and Salah al-Din. Overall, this finding confirm the results presented by Ghulam, et al. (2007a, b and 2008) and Qin, et al. (2008) for arid and semi-arid conditions that found throughout Iraq, the NDVI can used as simple and cost-efficient drought indices to monitor crop development stages in relation to rainfall during growing season. 

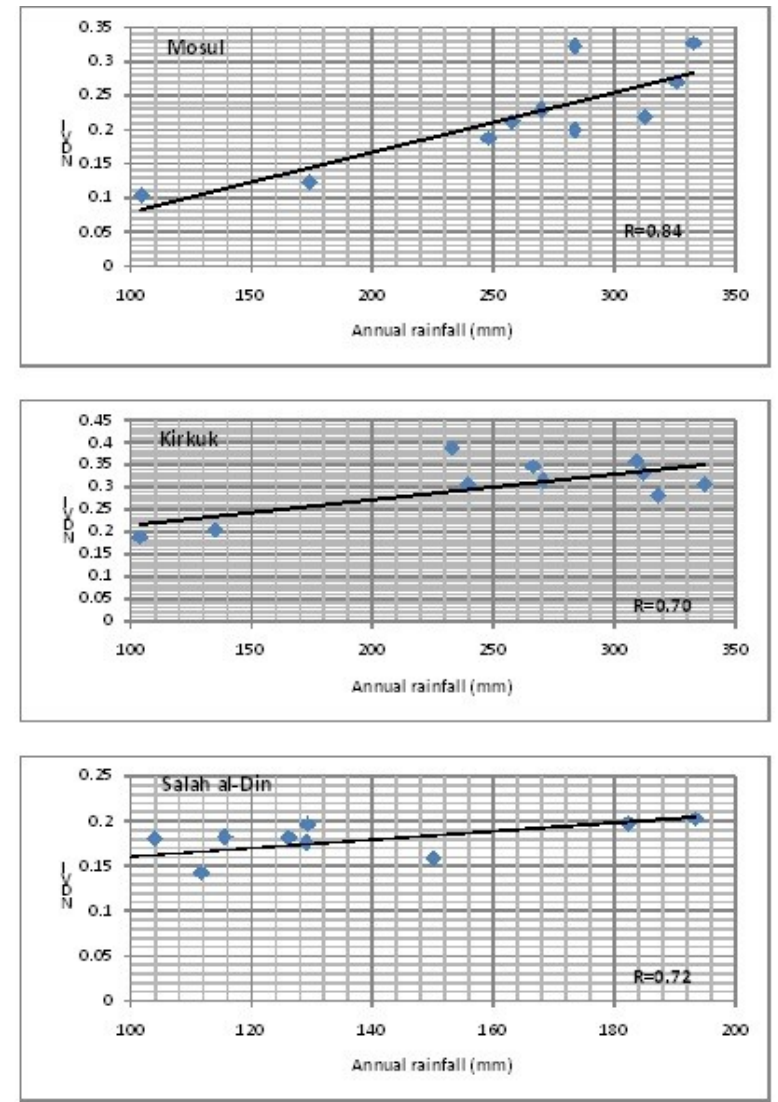

Figure (7): Correlation coefficient (r) between NDVI and annual rainfall for Mosul, Kirkuk, and Salah al-Din for period 2000-2010.

\section{4- Agricultural drought risk based on NDVI anomaly}

Monthly NDVI images were generated for all growing season (October through July). The month with maximum NDVI value (April) was selected to assess vegetation anomalies during the specific growing season (year). Time series of NDVI anomaly used to detect agricultural drought (Murad and Saiful Islam, 2011 and Chopra, 2006). The threshold values used in this study to classify agricultural drought risk using NDVI anomalies that presented in Table (2).

Table (3) shows the NDVI anomalies for the study area (Mosul, Kirkuk, and Salah al-Din). It is evident from figure that during the low rainfall years NDVI values were also low and two major years 2008 and 2009 are classified as very severe $\backslash$ severe drought for three governorates. It can be observed that during 2008-2009, whole of the study area had negative NDVI anomalies corresponding negative rainfall anomalies table (3). Vegetation shows a good response and NDVI values with rainfall amount, which confirmed that rainfall has a great impact on vegetation conditions. Further, same figure shows that Mosul had slight drought during 20052007 and moderately drought in 2010, where the years 2005, 2006, and 2007 were near normal years and slight drought in 2010 for Kirkuk, and Salah al-Din. Thus this study shows that the NDVI value is highly depend on average rainfall condition in a region. These results are in agreement with those reported by Li, et al. (2002) in China; Chopra (2006) in India and Shahabfar and Eitzinger (2011) in Iran. They found that the NDVI has positive relation to rainfall and NDVI is good indicator vegetation vigor. Further NDVI is excellent pointer to assess agricultural drought from the point of agricultural production and its linkages, so that the drought risk can be marked out taking into consideration the crop yield and describing an area at risk.

Table (3): Drought class based on NDVI anomalies for period (2001-2010).

\begin{tabular}{|c|c|c|c|c|c|c|}
\hline \multirow[t]{2}{*}{ year } & \multicolumn{2}{|c|}{ Mosul } & \multicolumn{2}{|c|}{ Kirkuk } & \multicolumn{2}{|c|}{ Salah al-Din } \\
\hline & NDVI anomaly & Drought category & NDVI anomaly & Drought category & NDVI anomaly & Drought category \\
\hline 2005 & $-9 \%$ & Slight & $4 \%$ & ------ & $1 \%$ & ------- \\
\hline 2006 & $0 \%$ & Slight & $1 \%$ & ------ & $4 \%$ & |------ \\
\hline 2007 & $-3 \%$ & Slight & $2 \%$ & ----- & $3 \%$ & ------- \\
\hline 2008 & $-53 \%$ & Very severe & $-38 \%$ & Very severe & $-26 \%$ & Severe \\
\hline 2009 & $-44 \%$ & Very severe & $-33 \%$ & Very severe & $-19 \%$ & Moderately \\
\hline 2010 & $-15 \%$ & Moderately & $-7 \%$ & Slight & $-9 \%$ & Slight \\
\hline
\end{tabular}




\section{5- NDVI -trends in terms of Soil Quality}

Soil is a dynamic resource that supports plant life (Soil Quality Institute, 2001). Thus, soil has measurable properties, some of which are dynamic and can change in response to management or climate. From agricultural view, soil quality is the capacity of soil to sustain plant and animal productivity. To evaluate soil quality, indicators can be monitored over time to establish trends of decline in productivity. Concerning drought management, decision-makers require data should be available and accessible for use in short period of time and need to be updated on the latest drought situation. NDVI time series proved to be most significant predictor of soil quality (by measured change in productivity with deviation from long-term mean); either as an index (Bai, et al., 2008 and Anyamba and Tucker, 2005) or as one input to dynamic vegetation models (Fensholt, et al., 2006 andHengl, et al., 2002).

To interpret NDVI trends in terms of soil quality, the linear trend of NDVI was adopted. The NDVI index reflects two impacts of climate change, affecting both on the supply of crop water demand and on soil biological processes, $\mathrm{C}$ and $\mathrm{N}$ cycling, and consequently on soil structure and nutrients availability.

Figure (8) shows NDVI-trends change. It can be clearly observed that the lowest productivity was in 2008 and 2009 for all study governorates, and the highest productivity was in 2001 for Mosul and Salah al-Din and in 2003 for Kirkuk. Although, the figure shows slightly increased in productivity of 2010 compared with years 2008 and 2009, but it is still less than of the productivity in 2001 and 2003. The negative trends in NDVI values mirror non-uniformity of rainfall patterns and moisture shortage during the growing season. The biomass status in 2010 highlighted that prolong of drought conditions in 2008 and 2009 caused losses in soil productivity (decline of soil quality) is cumulative. This issue should be addressed on a basis of soil time-series data.

These results verify needing to use this tools (NDVI) as effectively as to help mitigate the impacts of drought and maintain soil quality and productivity. Land managers can use long-term remotely sensed data, along with data from soil survey, fertility tests, and other monitoring data to identify areas with problem (where, when, and how problems arise) to make management decisions. Delay in data collection, access, usage has negative impacts on the quality of decision-making response. The advantages of using NDVI as a tool to predict soil properties with equal or high precision are confirmed by other scientist Hengl, et al. (2002) and Burrough (1993). They stated that the relations between the soil and climate change drivers (rainfall and temperature) are usually quadratic, logarithmic or inverse of these. They introduced it as effective way of mapping soil properties at particle details. Because the biomass trends depend on several factors (such as soil properties and crop type) other than climate change, the historically soil data are helpful (not available at country or governorates level) to take account of soil properties changes over the period. Thus, the main disadvantage is that NDVI does not tell us anything about what happening and causes biomass declining.

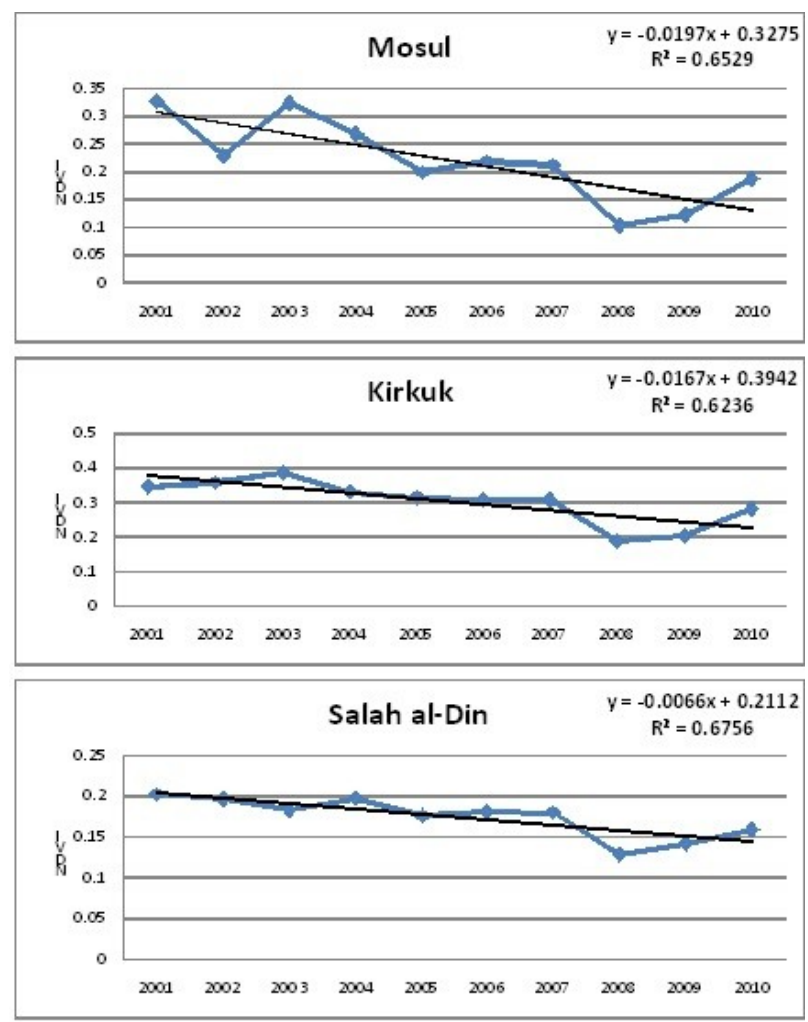

Figure (8): NDVI-trends change over period (2001-2010). 


\section{Conclusion}

Agricultural drought was categorized under this study using vegetation indices (NDVI). The highest NDVI values observed were 0.33 and 0.20 in the season 2000-01 for Mosul and Salah al-Din respectively, and 0.39 in 2002-03 for Kirkuk. The lowest NDVI values were in season 2007-08 for all governorates. Season 200708 started and ended with very unfavorable conditions making planting of crops difficult and reducing harvest. Whole of the study area had negative NDVI anomalies corresponding negative rainfall anomalies. The fluctuation of NDVI values were relative to the changes in local weather conditions in Mosul and Kirkuk, while the NDVI value showed a little stable patterns in Salah al-Din. The findings of NDVI analysis confirmed the sensitivity of this index to detect drought events and seasonal vegetation dynamics across all seasons.

The statistical relationship between NDVI and rainfall reflected by significance correlation coefficient values $0.83,0.70$ and 0.72 for Mosul, Kirkuk and Salah al-Din respectively. The study evaluated the effective of NDVI as an indicator of vegetation-moisture conditions

The study explained how the NDVI- negative trends reflect the impact of drought on soil quality, and highlighted that prolong of drought conditions in 2008 and 2009 caused losses in soil productivity (decline of soil quality) is cumulative. The main conclusion of this analysis was the historically soil data are helpful for monitoring agriculture drought.

\section{References}

[1]. Al-Agidi, W.K.(1986). Pedology: Soil survey and classification. Mosul Univ. Press, Iraq.

[2]. Anyamb, A. and Tucker, C. J. 2005. Analysis of Sahelian vegetation dynamic using NOAA-AHVRR NDVI data from $1981-2003$. Journal of Arid Environments, 63, 596-614.

[3]. Bai, Z. G. Dent, D. L. Olsson, L., Schaepman, M. E. (2008). Proxy global assessment of land degradation. British Society of Soil Science. Soil Use and Management, 24, 223-234.

[4]. Bajgiran, P. R. Darvishsefat, A. A. Khaliil, A. Makhdoum, M. F. (2008). Using AVHRR-based vegetation indices for drought monitoring in the northwest of Iran. Journal of Arid Environments, 72, 1086-1096.

[5]. Bhuiyan, C. Singh, R. P. and Kogan, F. N. (2006) .Monitoring drought dynamics in the Aravalli.

[6]. Burrough, P. A. 1993. The technologic paradox in soil survey: new methods and techniques of data capture and handling.ITC Journal (NO): 15-22.

[7]. Chopra, P.( 2006). Drought risk assessment using remote sensing and GIS, A case study in Gujarat, M. Sc. Thesis, Dept. of Geoinformation Science and Earth Observation, ITC, Netherlands.

[8]. Eastman, J. R. Sangermano, F. Ghimire, B. Zhu, H. L. Chen, H.andNeeti, N. et al. (2009). Seasonal trend analysis of image time series. International Journal of Remote Sensing. 30, 2721-2726.

[9]. Fensholt, R. and Proud, S. R. (2012). Evaluation of earth observation based on long term vegetation trends- comparing GIMMS and MODIS global NDVI time series. Remote sensing of Environment, 119, 131-147.

[10]. Fensholt, R. and Rasmussen, K.( 2011). Analysis of trends in the Sahelian 'rain-use efficiency' using GIMMS NDVI, RFE and GPCP rainfall data. Remote sensing of Environment, 115, 438-451.

[11]. Fensholt, R. Sandholt, I. Rasmussen, M. S. Stison, S. and Diouf, A. (2006). Evaluation of satellite-based primary production modeling in the semi-arid Sahel. Remote Sensing of Environment, 105, 173-188.

[12]. Ghulam, A. Qin, Q. and Zhan, Z.(2007a). Designing of the perpendicular drought index. Environmental Geology 52, $1045-1052$.

[13]. Ghulam, A. Qin, Q. Kusky, T. and Li, Z. L. (2008). A re-examination of perpendicular drought indices. International Journal of Remote Sensing 29, 6037-6044.

[14]. Goward, S.N. Markham, B. Dye, D.G. Dulaney, W. and Yang, J. (1991). Normalized difference vegetation index measurements from AVHRR. Remote Sensing of Environment, 35, 257-277.

[15]. Gross, D. (2005). Monitoring agricultural biomass using NDVI time-series. Food and Agriculture Organization of the United Nations (FAO), Rome.

[16]. Hengl, T. David, R. G. and Stjepan, H. (2002). Mapping soil properties from an existing national soil data set using freely available ancillary data. $17^{\text {th }}$ WCSS, $14-21$ August 2002, paper no. 1140 , Thailand.

[17]. IAU Report - Inter-Agency Information and Analysis Unit (October 2010), "Water in Iraq Fact sheet"

[18]. Inter-Agencey information and analysis Unit (IAU-Iraq). (2011). Salah ad-Din governorate profile. February, 2011.

[19]. Jain, S. K. Keshri, R. Goswami, and A. Sakar, A. (2010). Application of meteorological and vegetation indices for evaluation of drought impact: a case study for Rajasthan. India. Nat. Hazards, 54: 643-656.

[20]. Jain, S. K. Keshri, R. Goswami, A. Sarkar, A. and Chaudhry, A. (2009). Identification of drought-vulnerable areas using NOAAAVHRR data. International Journal of Remote Sensing, 30, No.10, 2653-2668.

[21]. Kogan,F. N. (1990). Remote sensing of weather change impact on vegetation index in non-homogenous areas. International Journal of Remote Sensing, Vol. 11: pp.1405-1421.

[22]. Li, B and S. Tao, et al. (2002). Relations between AVHRR NDVI and ecoclimatic parameters in China. International Journal of Remote Sensing Vol. 23 (5): pp. 989-999.

[23]. Li, J., J. Lewis et al.( 2004). Evaluation of land performance in Senegal using multi-temporal NDVI and rainfall series. Journal of Arid Environment, Vol. 59: pp. 463-480.

[24]. Martiny, N. Camberlin, P. Richard, Y. and Philippon, N. (2006). Compared regimes of NDVI and rainfall in semiarid regions of Africa. International Journal of Remote Sensing 27, 5201-5223.

[25]. Muhaimeed, A.S. (1991). Morphology and natural formation of some soils in northern Al-Jazera project. Iraqi J. Sci. 4:885895 .

[26]. Muhaimeed, A.S. (2012). Soil Resources of Iraq. In:

[27]. Muhaimeed, A.S. A.S. Al-Shikihi, S.K. Esa, and Jamal, M.A. (2000).Comparison of some properties of some properties of soils on both sides of great Zab river in Aski-Kalk. Zanco. 4:75-88.

[28]. Muhaimeed, A.S. and Mohammad, I.J. (2001). Characteristics, formation, and classification of alluvial soils of Naft valley in Manadali area. Iraqi J. Soil Sci. 1:138-144.

[29]. Murad, H. Saiful Islam, A. K. M. (2011). Drought assessment using remote sensing and GIS in north-west region of Bangladesh. 3rd International Conference on Water and Flood Management ((ICWFM), 
[30]. Murthy, C. S. SeshaSai, M. V. R. Chandrasekar, K. and Roy Owrangi, M. A. Adamowski, J. Rahnemaei, M. and Mohammadzadeh, A.( 2011). Drought monitoring methodology based on AVHRR images and SPOT vegetation maps. Journal of Water Resource and Protection, 3, 325-334.

[31]. Owrangi, M. A. Adamowski, J. Rahnemaei, M. and Mohammadzadeh, A. (2011). Drought monitoring methodology based on AVHRR images and SPOT vegetation maps. Journal of Water Resource and Protection, 3, 325-334.

[32]. Persendt, F. C.( 2009). Drought Risk Analysis using Remote Sensing and GIS in the Oshikoto Region of Namibia. M.Sc. thesis, Dept. of Environment and Development, University of KwaZulu-Natal, Pietermaritzburg.

[33]. PRT/USAID/RTI. 2007. Strategic planning of Kirkuk province. Approved by provincial council of Kirkuk province, the future vision of Kirkuk province, government of Iraq, Sept. 2011.

[34]. Qin, Q. Ghulam, A. Zhu, L. Wang, L. LI, J. and Nan, P. (2008). Evaluation of MODIS derived perpendicular drought index for estimation of surface dryness over northwestern China. International Journal of Remote Sensing 29, $1983-1995$.

[35]. Quring, S.M. and Ganesh, S. (2010). Evaluating the utility of the Vegetation Condition Index (VCI) for monitoring meteorological drought in Texas. Agricultural and Forest Meteorology 150, 330-339.

[36]. Rathore, M. S. (2004). State level analysis of drought policies and impacts in Rajasthan, India, Working paper 93, Drought Series. Paper 6 (India: International Water Management Institute).

[37]. Shahabfar, A. and Eitzinger, J. (2011). Agricultural drought monitoring in semi-arid and arid areas using MODIS data. Journal of Agricultural Science, 149, 403-414.

[38]. Shaheen, A. and Baig, M. A. (2011). Drought severity assessment in Arid Area of Thal Doab using remote sensing and GIS. International Journal of Water Resources and Arid Environments 1(2):92-101.

[39]. Tucker, C. J. (1979). Red and photographic infrared linear combinations for monitoring vegetation. Remote Sensing Environmental, $8: 127-150$.

[40]. United Nations Development Programme (UNDP).(2010). Drought impact assessment, recovery and mitigation framework and regional project design in Kurdistan region (KR). December 2010.

[41]. Vicente-Serrano, S. Cuadrat-Prats, J.M. and Romo, A. (2006). Early prediction of crop productivity using drought indices at different time scales and remote sensing data: application in the Ebro valley (north east Spain). International Journal of Remote Sensing, 27, pp. 511-518.

[42]. Yan, W. Yang, L. and Merchant, J.M. (1998). An assessment of AVHRR/NDVI ecoclimatological relations in Nebraska, USA. International Journal of Remote Sensing 18 (10), 2161-2180. 